\title{
Why people donate their brain to science: a systematic review
}

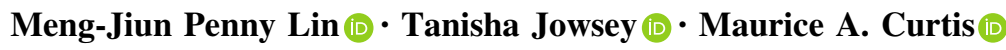

Received: 28 January 2019/Accepted: 5 September 2019/Published online: 19 September 2019

(C) The Author(s) 2019

\begin{abstract}
The acquisition of brain tissue for research purposes is an important endeavour in research on ageing, pathological diagnosis, and the advancement of treatment of neurological or neurodegenerative diseases. While some tissue samples can be obtained from a living patient, the procurement of a whole brain requires the donation from people after their death. In order to promote positive attitudes towards brain donation, it is essential to understand why people do or do not donate their brain to medical research. In 2018 we undertook a systematic review of the international literature concerning people's attitudes, motivations, and feelings about brain donation. Five electronic databases were searched: Scopus, PsycINFO, Embase, Medline, and Google Scholar. Search terms included:
\end{abstract}

M.-J. P. Lin ( $\square)$

School of Curriculum and Pedagogy, Faculty of

Education and Social Work, The University of Auckland, Auckland, New Zealand

e-mail: penny.lin@auckland.ac.nz

T. Jowsey

Faculty of Medical and Health Sciences, Centre for Medical and Health Sciences Education, The University of Auckland, Auckland, New Zealand

e-mail: t.jowsey@auckland.ac.nz

M. A. Curtis

Anatomy and Medical Imaging, Faculty of Medical and Health Sciences, The University of Auckland, Auckland,

New Zealand

e-mail: m.curtis@auckland.ac.nz ("brain donor*" OR "brain donation" OR "brain banking" OR "banking on brain") AND (attitude* OR motivation* OR decision*") AND (LIMIT-TO "human”) AND (LIMIT-TO (LANGUAGE, "English”)). Articles were analysed using the Framework for Assessing Qualitative Evaluations and a meta-ethnographic approach. Fourteen articles were included for review. The findings suggest four universal factors informing a person's decision to donate their brain: (1) contextual knowledge, (2) conceptual understandings, (3) family/friends matter, and (4) personal experience, time and process. The findings also indicate that the way healthcare professionals present themselves can influence people's feelings and attitudes towards brain donation. Healthcare and research professionals who are involved in brain donation processes must be mindful of the complex and multiple factors that influence donation outcomes. Effective and sensitive communication with potential donors and their family/ friends is paramount.

Keywords Brain donation - Donor - Attitudes · Motivations · Barriers · Review · Meta-ethnography · Framework for Assessing Qualitative Evaluations (FAQE) 


\section{Introduction}

Advances in medical science often stem from research conducted on human tissue and organs. There is an ever-present tension between the importance of generating sufficient tissue, samples or specimens for "societal and ethically crucial goods and the rights of individuals or their families to control the use of such material" (Price 2010, p. 3). Notwithstanding, donated organs and tissue offer incalculable benefits to humankind for therapeutic or research purposes (Azizi et al. 2006; Eatough et al. 2012; Harris et al. 2013; Price 2010). Without reservation, brain donors are important. Their donated brains can provide vital clues about neurodegenerative diseases, and new studies can potentially advance treatment. Typically, brain banks depend heavily on donation awareness among potential donors and relatives (Eatough et al. 2012). Information about the importance of brain donation is usually provided through related organisations' newsletters, speeches by researchers, and community outreach programmes (Eatough et al. 2012; France et al. 2017).

While ample studies reveal the motivations of transplant donors, less is known about the factors motivating people to donate organs for research purposes (Kuhta et al. 2011). People with neurological disorders or mental illnesses are often motivated to donate their brain after death (Azizi et al. 2006; Boise et al. 2017; Boyes and Ward 2003; Harris et al. 2013; Lambe et al. 2011). In contrast, there has been a critical shortage of neurologically healthy brains donated, and these brains are important for comparative work and understanding normal brain processes (Schmitt et al. 2001). Globally, public awareness and knowledge about brain donation is low. Most people are more familiar with the concept of organ donation for transplantation than of brain donation. Researchers are calling for public promotion of brain donation (Azizi et al. 2006; Eatough et al. 2012; Harris et al. 2013; Padoan et al. 2017). Understanding why people do or do not donate may assist professionals to coordinate and facilitate public education programmes about brain donation for research (Azizi et al. 2006).

We undertook a systematic review to identify what is known about factors influencing individuals' or families' decisions about brain donation for research purposes. Some research suggests that brain donation may hold more special personal significance for people than other organ donations (Boyes and Ward 2003; Nussbeck et al. 2015). To date, there has been no systematic assessment in this area.

This article reports on the results of a systematic review of the international literature that used qualitative and mixed methods research to identify people's attitudes, motivations, and feelings about donating their or their loved ones' brain to medical research. Our research question was: what are the factors people consider important in deciding whether or not to donate their or their loved ones' brain for research? We limited the review to qualitative and mixedmethods research because we were interested in the voices of potential donors and their families which is strongly evident in these types of research.

\section{Methods}

The review followed four procedural steps: (a) comprehensive search (b) quality appraisal, (c) synthesis of findings, and (d) critical appraisal.

\section{Search process}

In May 2018 five electronic databases were searched: Scopus, PsycINFO, Embase, Medline, and Google Scholar. A systematic literature search method was utilised to capture the relevant studies that contained the desired terms in the title, abstract, or keywords. Search terms included: ("brain donor*" OR "brain donation" OR "brain banking" OR "banking on brain") AND (attitude* OR motivation* OR decision*") AND (LIMIT-TO "human") AND (LIMITTO (LANGUAGE, “English”)).

Inclusion and exclusion criteria

No limits were used for time or type of source. The exclusion terms were: (brain dead OR brain death).

Articles written in English were included. The final selection of articles was made using the following inclusion criteria: (1) the study explored the views/experience of potential brain donors about brain donation for research; (2) the study identified the views/experience of brain donors' families about brain donation for research; (3) the study used qualitative or mixed methods approach. 
The initial search identified 219 possible articles. Three rounds of the selection process (Fig. 1) were followed. First, we excluded clinical studies based on a Brain Bank database; reports on Brain Bank programmes; reviews on practical aspects of acquisition and storage of donated brains; and duplicate articles. Second, we excluded letters, reports and advertisements. Finally, the remaining articles were screened for relevance to our research questions.

Evaluation of sources

\section{Quality appraisal}

We used the Framework for Assessing Qualitative Evaluation (FAQE) (Spencer et al. 2003) to appraise the quality of the included literature. The FAQE assesses methodological quality in terms of findings, design, sample, data collection, analysis, reporting, reflexivity and impartiality. We identified this tool as being especially useful for this review due to its appraisal questions and quality indicators for evaluation, which are specific to qualitative research. The FAQE has been used effectively for appraising qualitative research in other research (MacEachen et al. 2006).

\section{Rigour}

To ensure the suitability and credibility of FAQE, it was compared with the Standard for Reporting Qualitative Research checklist (SRQR) (O'Brien et al. 2014, p. 1245) where standards for reporting qualitative research are listed. We used both tools,

\section{Systematic literature Search}

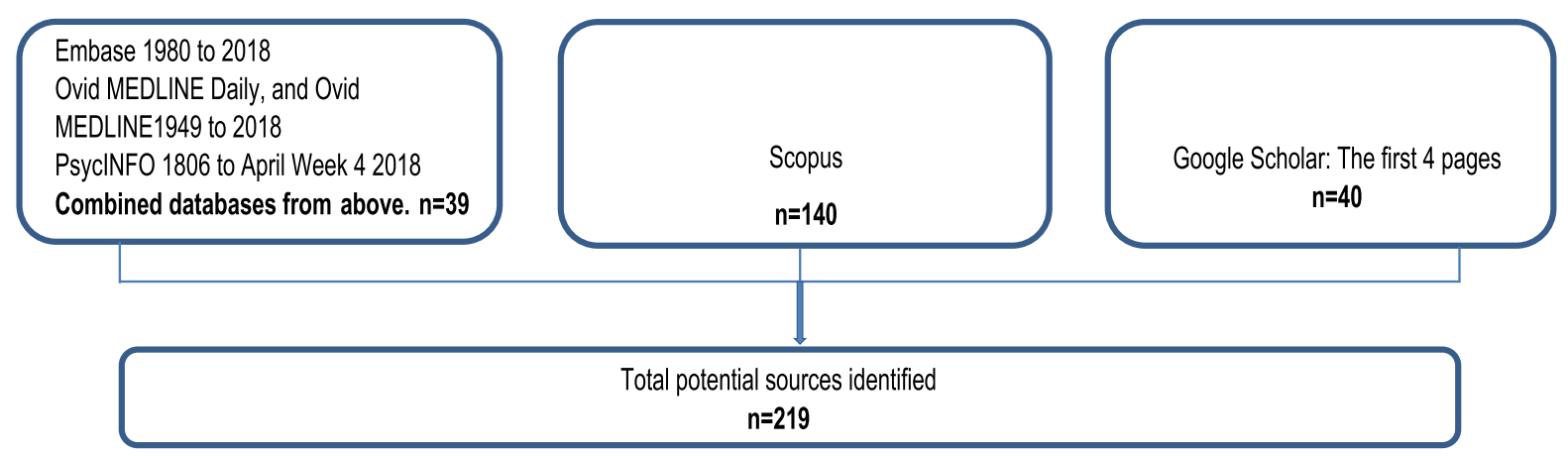

\section{Selection process}

$1^{\text {st }}$ selection procedure: Excluded clinical studies using Brain Bank database, reports on Brain Bank programmes, and reviews on the practical aspects of acquisition and storage of the donated brain. Duplicate papers removed. $n=42$

\section{$2^{\text {nd }}$ selection procedure: Excluded letters, reports, and advertisements. $n=32$}

$3^{\text {rd }}$ selection procedure: The full text of the 32 papers were screened to identify their research paradigms. It further excluded reports and a review; this yielded 26 primary research papers. Of these, 12 quantitative, 8 qualitative and 6 mixed methods papers were identified. Within which, the qualitative and mixed methods papers were included for the quality assessment. $n=14$

\section{Quality appraisal}

Assessed quality of the relevant studies and noted as medium, high and very high.

\section{Evidence synthesis}

Using relevant studies to develop summary tables and complete evidence synthesis

Fig. 1 Flowchart of studies included in the literature review 


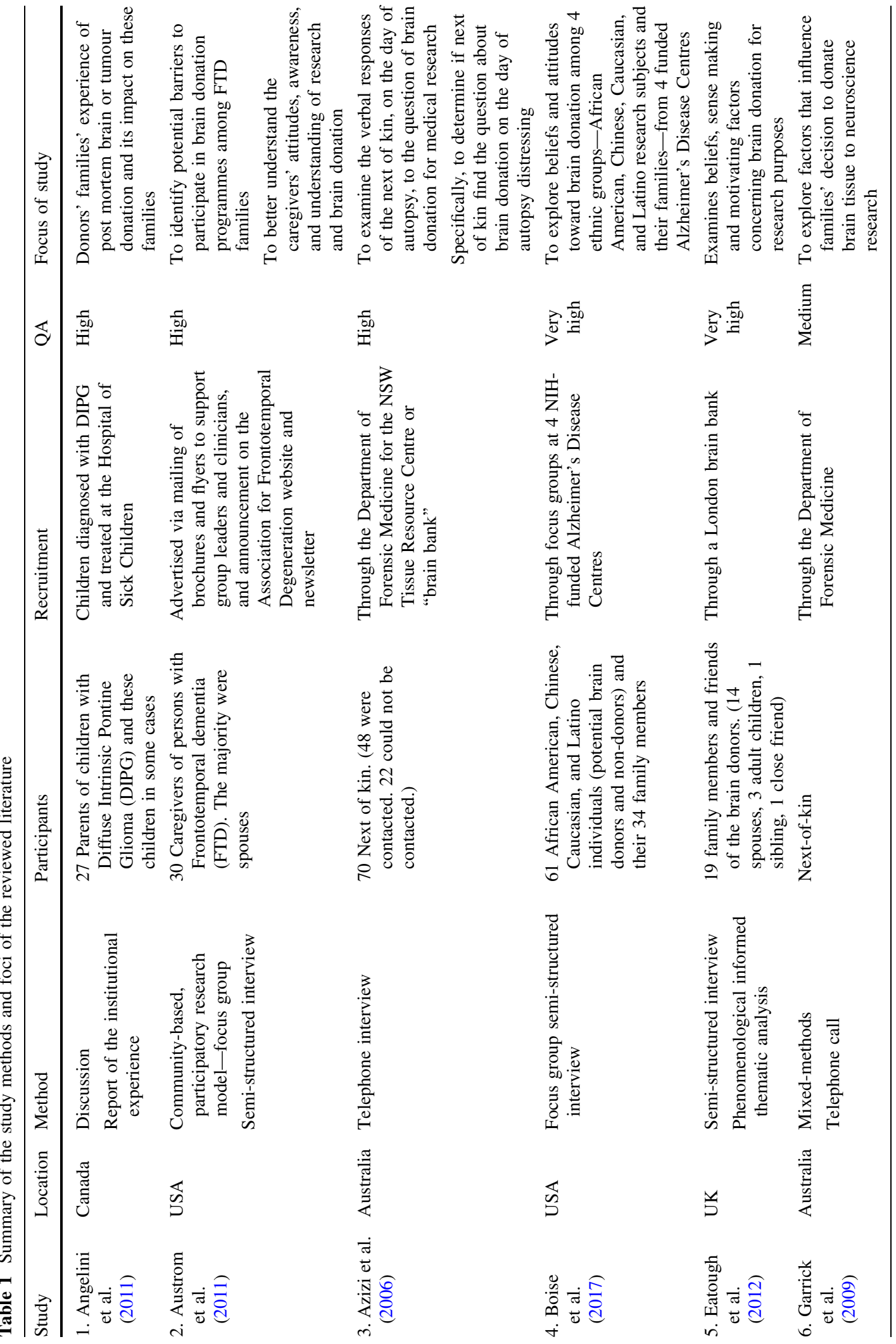




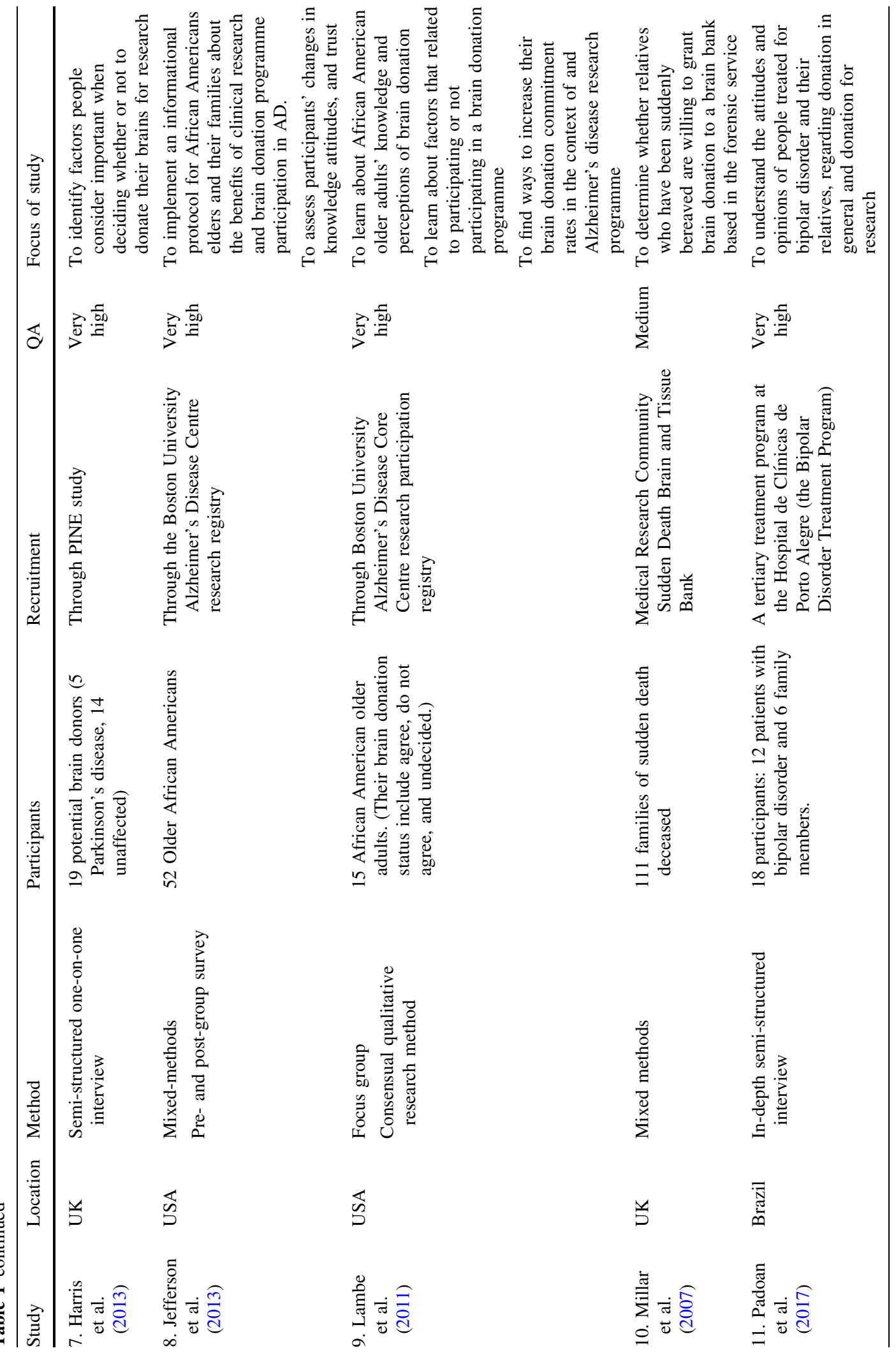




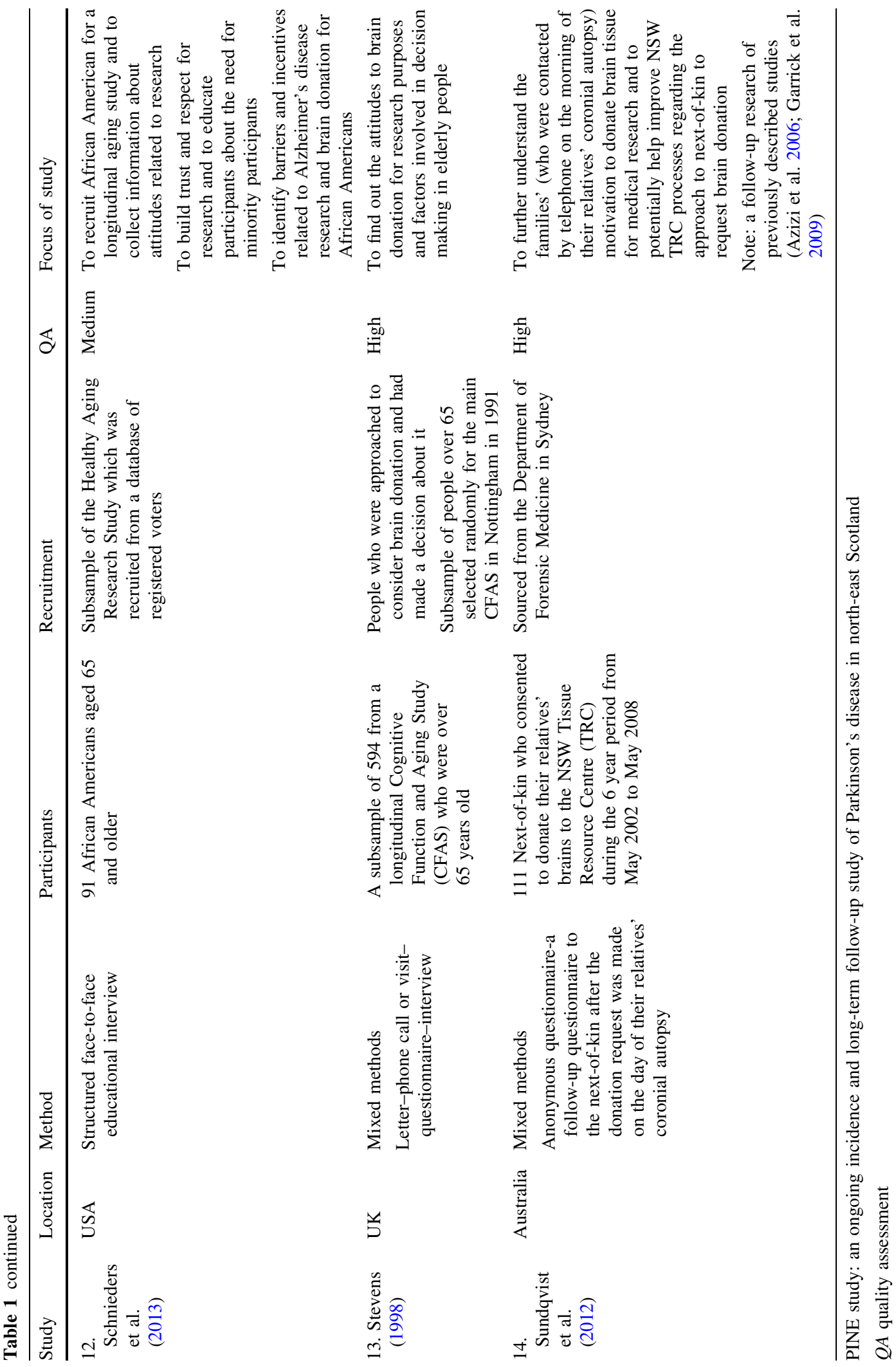


FAQE and SRQR, on three of the articles selected for this review and compared findings. We decided to utilise the FAQE on the basis that it was more robust and detailed than the SRQR. This decision reflects MacEachen et al.'s (2006) assertion that FAQE acknowledges the "iterative and creative nature of qualitative research" because it offers a guideline for systematic consideration of papers rather than a checklist of the procedure (p. 258).

\section{Qualitative focus}

The FAQE focuses on qualitative research. We decided to use the FAQE and to focus on the review to qualitative and mixed-methods research because we were interested in the voices of potential donors and their families which is strongly evident in these types of research. Some of the excluded quantitative studies feature instead in the introduction and discussion sections of this paper.

\section{Guiding principles}

There are four central principles that underpin the content of the FAQE (Spencer et al. 2003). They advise that research should be:

1. Contributory in advancing wider knowledge or understanding about policy, practice, theory or a particular substantive field;

2. Defensible in design by providing a research strategy that can address the evaluative questions posed;

3. Rigorous in conduct through the systematic and transparent collection, analysis and interpretation of qualitative data; and

4. Credible in claim through offering well-founded and plausible arguments about the significance of the evidence generated. (p. 7)

These guiding principles include 18 appraisal questions ("Appendix 1"), each of which includes between four and seven quality indicators. The selected articles were reviewed independently by two members of the team (authors 1 and 2). These papers were assessed and noted to be medium, high, or very high in quality (see Table 1: Summary of study methods and foci for the validity assessment guidelines). The quality of the appraisal results was discussed by the two authors who conducted the appraisal to achieve concordance as a measure of the credibility of the data. If a consensus could not be reached, we planned for a third reviewer to be consulted. However, consensus was reached for each paper.

\section{Data extraction}

As the data extraction progressed, the extracted information was stored in an Excel spreadsheet. The extraction included the focus of the research, method, theoretical orientation, sampling, context, analysis, findings, and researchers' reflections. Extractions were initially conducted by the first author; later, meetings with the other authors were held to discuss the grouping of the themes. Data extracted from the selected sources were further arranged into two tables. Table 1: Summary of the study methods and foci; and Table 2: Factors influencing brain donation decision.

Synthesis of studies: meta-ethnographic approach

We used the meta-ethnographic approach to synthesise the data from articles included in this review. The meta-ethnographic analysis involves collating and synthesising findings from multiple published studies. The strength of this approach is that it applies a general interpretive lens for synthesising findings across multiple qualitative approaches (such as ethnography, grounded theory, or other interpretive approaches) and paradigms (Noblit and Hare 1988). It can also cater to qualitative data in diverse formats, such as interview transcripts, tabulated and descriptive notes, and matrices (Noblit and Hare 1988). It privileges comparison, interpretation, synthesis, and reciprocal translations of the meanings between and/or among the cases studied (Noblit and Hare 1988). This approach enables a rigorous procedure for interpretations about ethnographic and interpretive studies; it is "like the quantitative counterparts of meta-analysis" (Noblit and Hare 1988, p. 9). The meta-ethnographic approach has been used in other systematic reviews of the qualitative health literature (MacEachen et al. 2006). The meta-ethnographic approach "can lead to a synthesis and extension of qualitative research in a defined field of study" (Campbell et al. 2003, p. 671).

For the purpose of conducting a meta-ethnography, Noblit and Hare (1988) describe three different types of synthesis. The first is achieved through reciprocal 


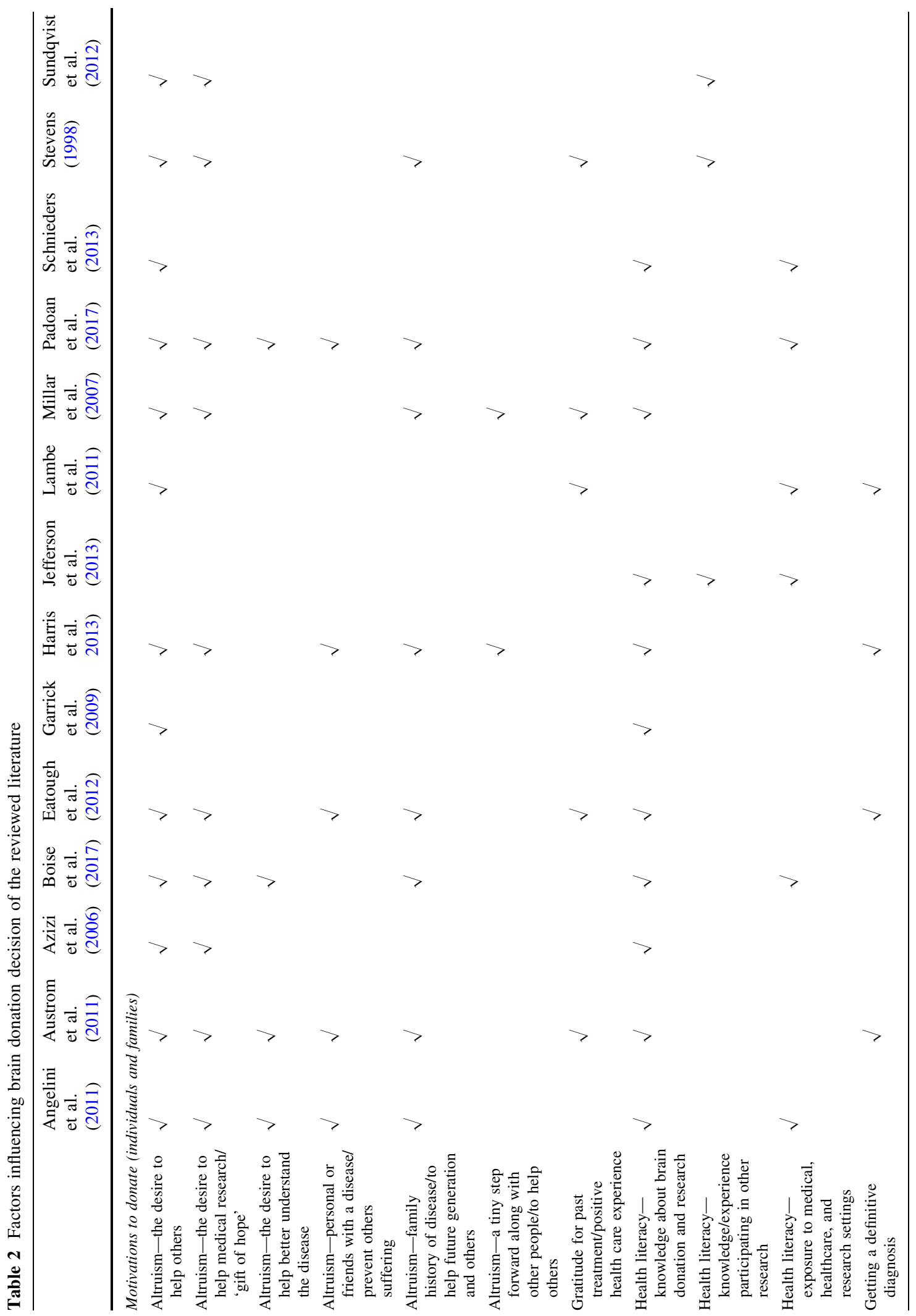




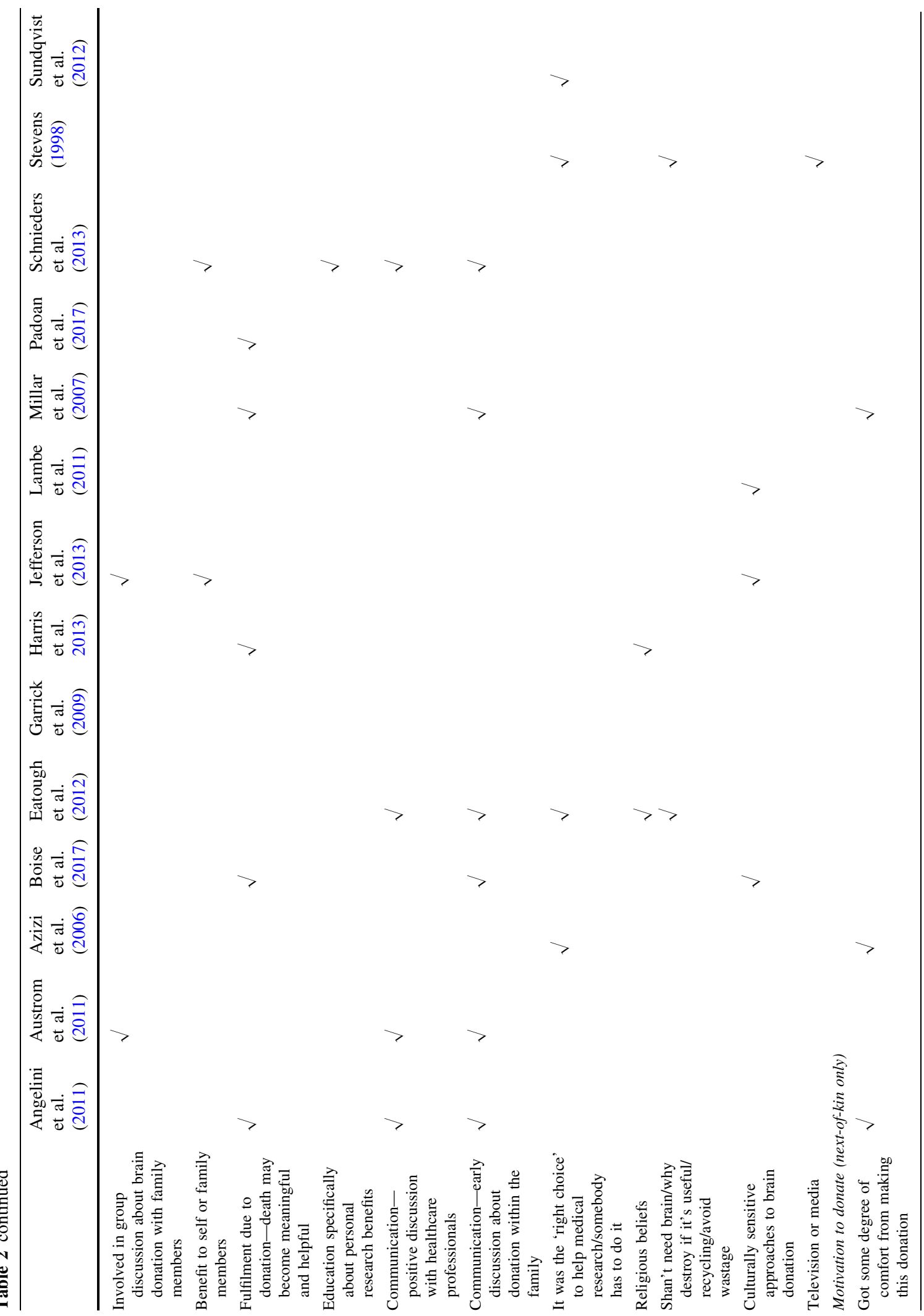




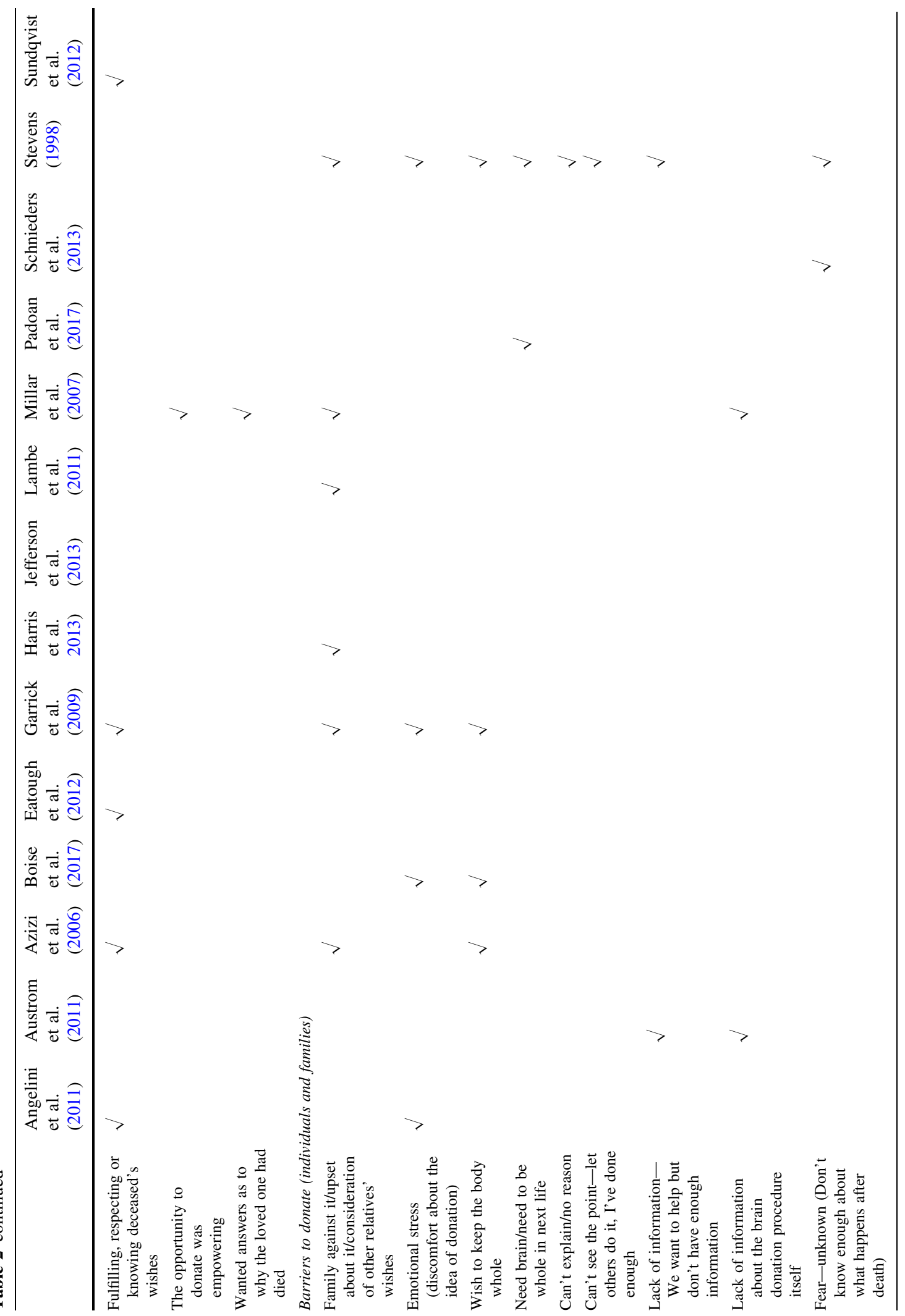




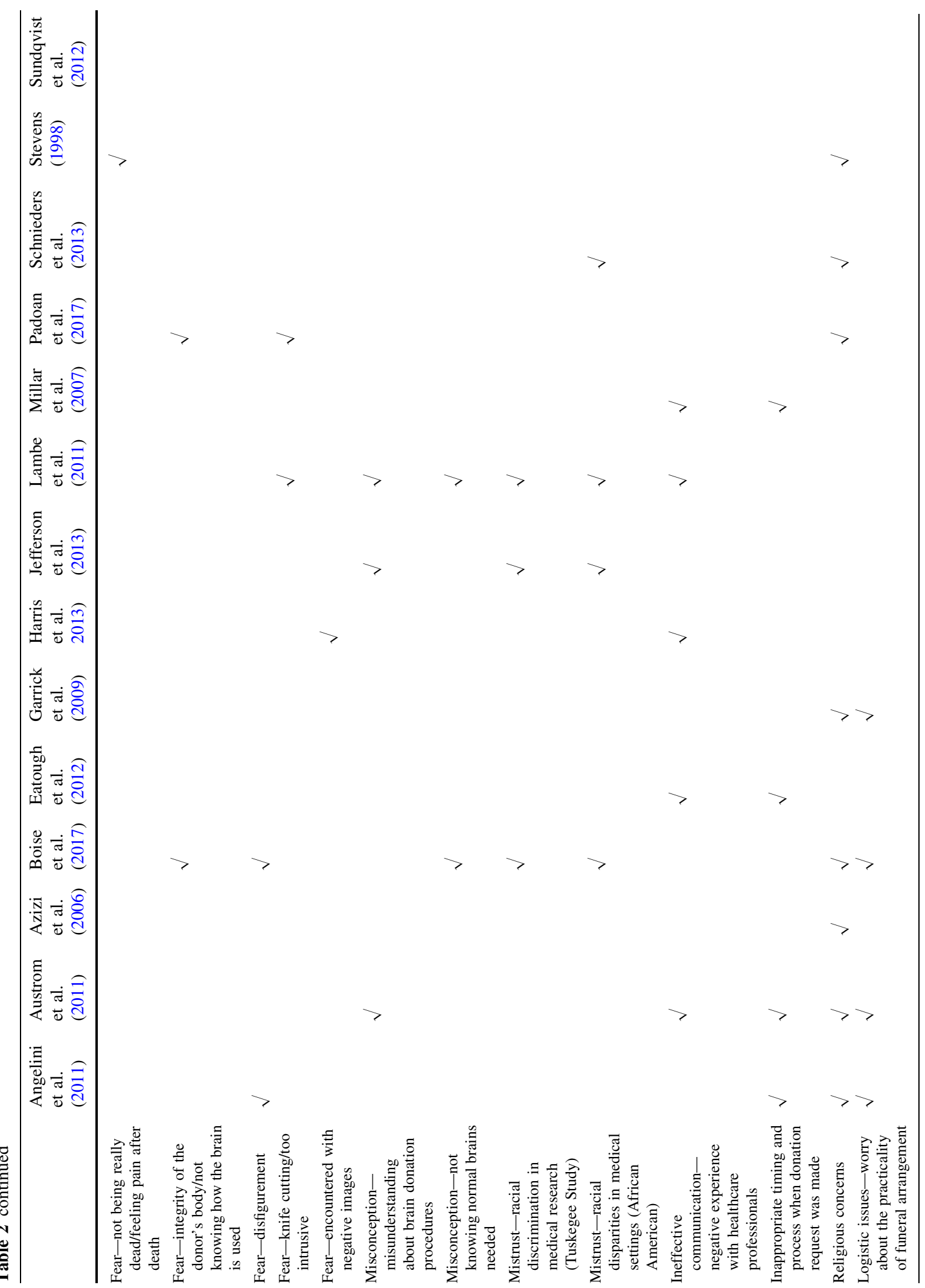




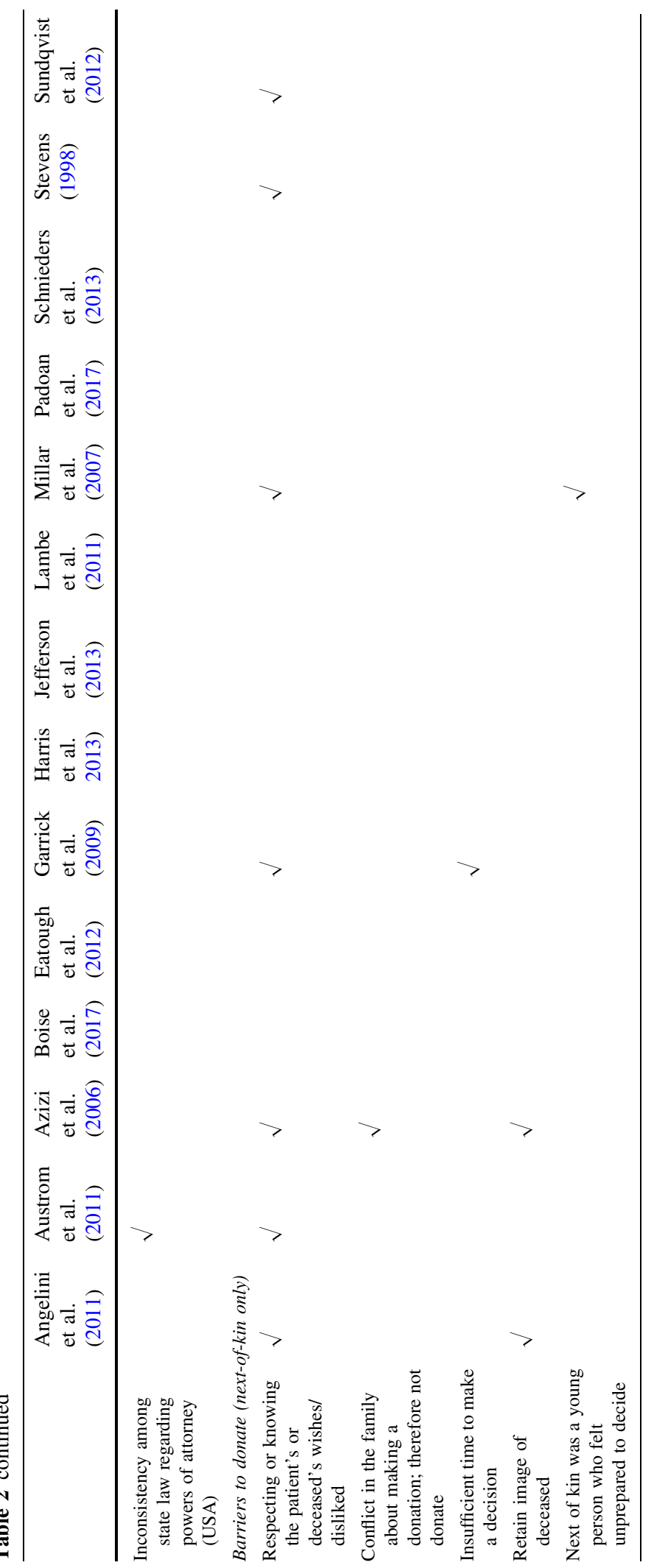




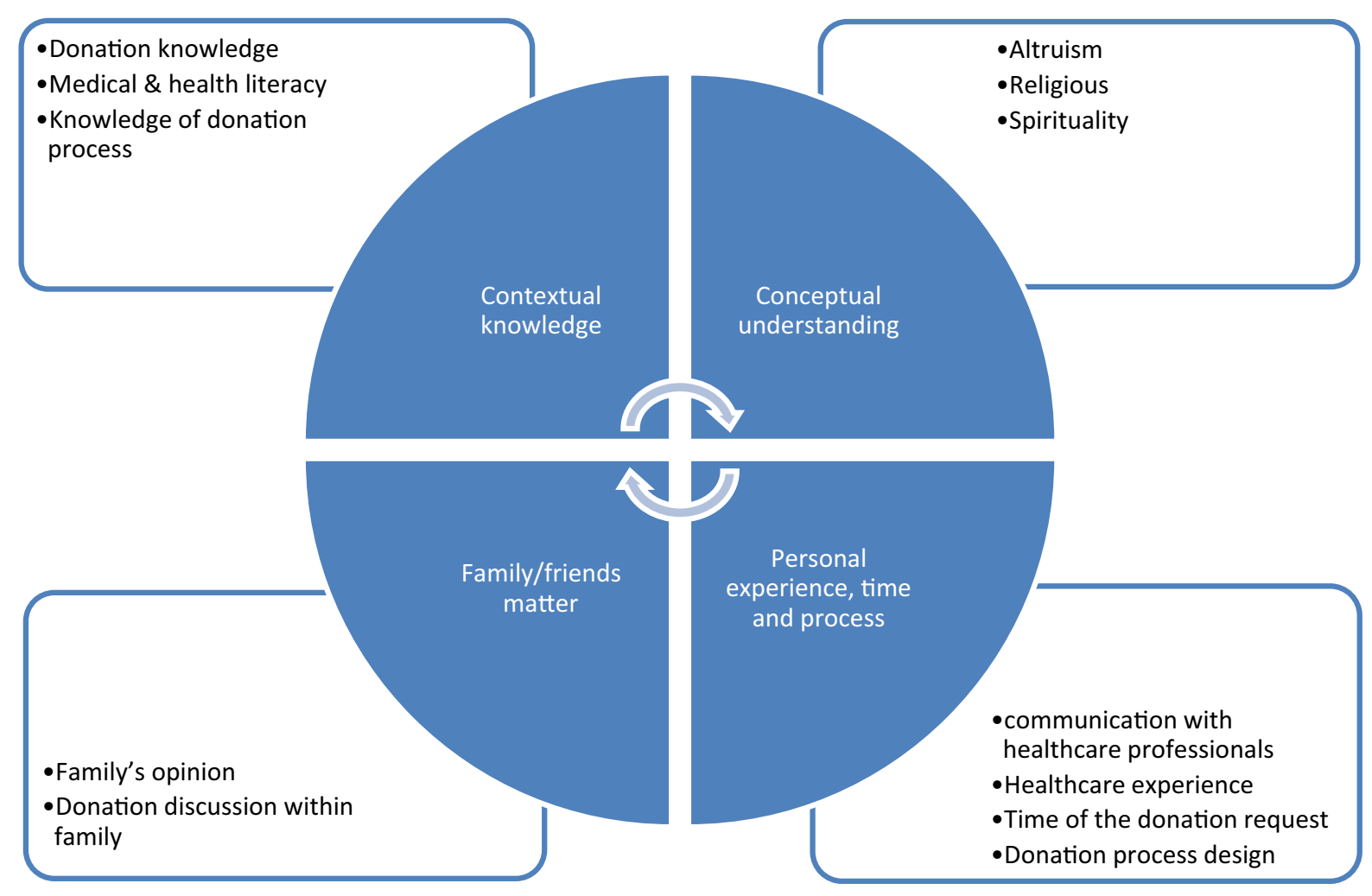

Fig. 2 Our framework of how the brain donation decision works

translation when the concepts contained in the papers are similar and thus are directly comparable. The second is when the accounts stand in relative opposition, in which case a two-sided refutational synthesis can be engaged. In the third, the studies are combined to represent a 'line of argument' synthesis, where repeated comparisons between studies were accomplished. In this review, data extraction provides the first form of synthesis. A two-sided refutational synthesis was used to discuss the contextual factors influencing decisions about the donation of the brain; they can be the motivations or barriers to donating. Later, following Glaser and Strauss (2017), our review reports on the findings from a synthesis of the selected studies, aiming to achieve a 'line of argument' synthesis by recognising the similarities and differences among the studies.

\section{Findings}

Fourteen articles were included for review, including nine qualitative (Angelini et al. 2011; Austrom et al.
2011; Azizi et al. 2006; Boise et al. 2017; Eatough et al. 2012; Harris et al. 2013; Lambe et al. 2011; Padoan et al. 2017; Schnieders et al. 2013) and five mixed methods studies (Garrick et al. 2009; Jefferson et al. 2013; Millar et al. 2007; Stevens 1998; Sundqvist et al. 2012). Of these, the FAQE identified six as very high quality (Boise et al. 2017; Eatough et al. 2012; Harris et al. 2013; Jefferson et al. 2013; Lambe et al. 2011; Padoan et al. 2017), five as high quality (Angelini et al. 2011; Austrom et al. 2011; Azizi et al. 2006; Stevens 1998; Sundqvist et al. 2012) and three as medium quality (Garrick et al. 2009; Millar et al. 2007; Schnieders et al. 2013) (Table 1). The earliest included article was published in 1998 by Stevens. Health literacy featured in all fourteen articles and altruism featured in thirteen articles as key motivations to donate (Table 2). Six articles described what motivated family (next-of-kin) to agree to the donation (Angelini et al. 2011; Azizi et al. 2006; Eatough et al. 2012; Garrick et al. 2009; Millar et al. 2007; Sundqvist et al. 2012). Thirteen articles identified deterrents to donation (excluding Sundqvist et al. 2012) and four of these stood out as 
listing considerably more deterrents and detail about them than other articles did (Austrom et al. 2011; Boise et al. 2017; Lambe et al. 2011; Stevens 1998). Commonly reported barriers to donation were 'family against it' (Azizi et al. 2006; Garrick et al. 2009; Harris et al. 2013; Lambe et al. 2011; Millar et al. 2007; Stevens 1998), 'religious concerns' (Angelini et al. 2011; Austrom et al. 2011; Azizi et al. 2006; Boise et al. 2017; Garrick et al. 2009; Padoan et al. 2017; Schnieders et al. 2013; Stevens 1998), and 'ineffective communication with healthcare professionals' (Austrom et al. 2011; Eatough et al. 2012; Harris et al. 2013; Lambe et al. 2011; Millar et al. 2007) (Table 2).

Key concepts and meta-ethnographic synthesis

Following the meta-ethnographic approach, our findings suggest four universal factors informing individuals' or families' decision to donate their brain: contextual knowledge, conceptual understandings, family/friends matter, and personal experience, time and process (Fig. 2).

\section{Contextual knowledge: health literacy}

Bilbrey et al. (2018) assert that health literacy-the skills to access, read, process, understand, and communicate health related information-regarding brain donation can impact people's decisions concerning brain donation. Although the health literacy of potential donors and their family members was not measured in any of the 14 included studies, participant knowledge about brain donation clearly varied from low to high. Participants who demonstrated high brain donation health literacy tended to describe their motivations to donate in terms of a desire to support research and to advance treatment (Angelini et al. 2011; Azizi et al. 2006; Boise et al. 2017). In the case of potential brain donors with healthy brain, Harris et al. (2013) explain that their participants understood "the valuable contribution the donated 'normal' tissue could make to the understanding of the pathological process" that underlie neurodegenerative disease (Harris et al. 2013, p. 1101). In contrast, five studies reported that prior to participation in their study participants had little knowledge about brain donation for research (Bilbrey et al. 2018; Boise et al. 2017; Harris et al. 2013; Jefferson et al. 2013; Stevens 1998).
This finding is confirmed by broader literature: Garrick et al. (2006) write, "brain donation is a less familiar process to most of the population and is probably a more difficult personal decision that requires deliberation and consultation with loved ones" (p. 527).

Participants generally demonstrated more knowledge about organ donation for transplant purposes than brain donation for research purposes (Boise et al. 2017; Garrick et al. 2009; Harris et al. 2013; Stevens 1998). Some participants suggested that organ donation was (only) for anatomy education (Padoan et al. 2017). Others thought that the only use for donated organs was transplantation and this informed their ideas about whether donation was a viable path for them. For example, Stevens (1998) reports that many elderly respondents believed that no 'parts' of them would be 'good' for donation. Similarly, some people with bipolar disorder believed that they could not donate organs for transplantation because of their disease (Padoan et al. 2017). On learning about the prospect of brain donation, both sets of participants in these two studies were pleased to learn that they could be eligible to donate their brain for research purposes (Padoan et al. 2017; Stevens, 1998).

\section{Conceptual understandings}

Donating one's brain for research was referred to as a "gift of hope" by W. W. Tourtellotte, who initiated the collection of brain tissue for research in 1961 (Boyes and Ward 2003). All included articles presented potential donors' and donors' families' views of organ donation as a categorically 'good act' and altruistic. The main reported motivation of participants across all 14 studies was desire to help others. A participant expressed the donation act as "a tiny step forward along with other people" (Harris et al. 2013, p. 1101) In other cases, families consented to donate based on the knowledge that autopsy is the only way to make a definite diagnosis of certain diseases and such knowledge - particularly of hereditary diseases-could be important for future generations (Austrom et al. 2011; Eatough et al. 2012). Boyes and Ward (2003) explain that most people with chronic illness and their carers "regard research as a source of hope for amelioration of the distress" caused by it, and that "becoming a brain donor gives them a sense of being able to contribute" to the community they depend on (p. 166). 
This finding is echoed by Azizi et al. (2006), who explain the principal motivation given by the participants was "because of the desire to help medical research" and that the donation gave a positive outcome to the death (p. 451).

In other cases, researchers assert that for parents of diffuse intrinsic pontine glioma (DIPG) children who consented to donation, the donation decision helped "to make sense of their child's death, and fostered bereavement" (Angelini et al. 2011, p. 80). The families derived comfort from the hope that scientific breakthroughs could be made and felt that they were helping to make a difference in the advancement of the management of DIPG. In the case of two sets of parents, each set was particularly proud of their male child who expressed the wish to donate his brain to research. They shared memories with the team who treated their child and expressed appreciation to the palliative care team who offered end-of-life and home care. Angelini et al. (2011) conclude that the families' meetings with the healthcare professionals, from the treatment to end-of-life care to the donation process, were important for bereavement purposes.

\section{Family/friends matter}

The decision-making about brain donation for research takes place in two ways; either by the individual prior to death or by their family (usually, the next of kin) following death (Azizi et al. 2006; Boise et al. 2017). Family opinions-support or objections-for brain donation was well recognised across the 14 included studies as highly influential over donation outcome. Four included articles looked at this issue reasonably closely (Eatough et al. 2012; Harris et al. 2013; Lambe et al. 2011; Stevens 1998). Two studies questioned whether the individual or family's preference should prevail (Boise et al. 2017; Harris et al. 2013). One study found that some donors resented the possibility that their children could or might influence the donation outcome (Stevens 1998).

Multiple studies indicated that family discussion and making the decision prior to the individual's death promoted positive donation outcome and positive family experience (Azizi et al. 2006; Boise et al. 2017; Harris et al. 2013; Lambe et al. 2011; Stevens 1998). Azizi et al. (2006) state that "knowledge of the deceased's wishes regarding organ donation was the main reason given by families when making their decision" to give or deny consent for brain donation (p. 451). In one study, a donor's husband, Peter recalled:

For one short moment ... I had a sudden thought should I go ahead with it or shouldn't I ... I'm glad that I didn't waver and in fact I went ahead with her wishes and that I think it was the right thing for me (Eatough et al., 2012, p. 1280).

This example is consistent with the finding that having enough information about the deceased's wishes increased family satisfaction with the decision (Stevens 1998). Sundqvist et al. (2012) write, "Almost a quarter $(24 \%)$ commented that they had decided to donate because they were either aware that their deceased relative had wanted to be an organ donor, or believed it was something he or she would have wanted" (p. 95). Discussions within the family and knowing the deceased's wishes were also reported as influential in coronial autopsy settings where the donation of brain tissue to medical research was requested on the day of autopsy (Azizi et al. 2006; Sundqvist et al. 2012).

In some instances, the brain donation decision was made based on "a shared implicit understanding", values, and beliefs between the individuals and their family members (Eatough et al. 2012, p. 1279).

Personal experience, time and process

Personal experience, including healthcare and hospital experience, and the manner of the donation invitation/ request, affects people's donation decision (Angelini et al. 2011; Austrom et al. 2011; Azizi et al. 2006; Eatough et al. 2012; Sundqvist et al. 2012). The combination of the quality and timeliness of the invitation/request, and the environment in which the invitation is given/received influenced the response. For example, Eatough and colleagues report the experience of a non-donor participant who received a donation request via her mobile phone while in a supermarket car park. Despite the participant suggesting a call back, the clinician insisted on carrying on. The participant reflected on the conditions that might have encouraged people to donate; "you'd have to be with somebody and see their face, look at them, and get to know them a little bit even ... There's certain things you can't say to people without prejudging a 
little bit beforehand and sizing them up to find out if they can take it" (Eatough et al. 2012, p. 1278).

In other cases, families felt that the funeral directors did not take the donation act seriously. Elizabeth, wife of a donor, recalled:

I said his brain has to go for research, now, I actually got the forms out and this bloke looked at me as much as to say you'll be lucky ... I'm really upset about this because the only wish Bill had got in his life was that his brain was to go for research. I had a fight on my hands ... I had to do as he wished, I pushed heaven and earth (Eatough et al., 2012, p. 1281).

Based on such accounts, Eatough and colleagues urged that quality of communication and practice (including processes) amongst relevant healthcare professionals can be critical to informing donation outcome. They state that "Healthcare and related professionals need to be aware of the significance of [the donation] act and recognise their responsibility in ensuring that the process brings comfort rather than distress", and argue for "the need for privacy and empathy" when the donation invitation is made (Eatough et al. 2012, p. 1278).

In contrast, a positive experience of the brain donation request can encourage consent to donate. For example, a potential donor describing the healthcare professional who invited them exclaimed, "I couldn't have wished for anyone kinder" (Eatough et al. 2012, p. 1278). In another study, a family member expressed appreciation that the researchers gave the family information about brain donation and research ahead of time: “... had she just passed, and then you guys brought a paper to me saying, 'Your mum's agreed to donate,' that would be very hard for me... So I appreciate you guys taking the time to do this" (Boise et al. 2017, p. 724). Thus, the importance of providing potential donors and their families a positive communication experience-in a timely manner-is emphasised (Azizi et al. 2006; Eatough et al. 2012).

One included study reported that several next of kin participants said they would have liked more time to make decisions (Sundqvist et al. 2012). Timing for families and for researchers is important. The researchers explain that those next of kin contacted by the NSW Tissue Resource Centre in Australia during their relative's autopsy are almost always required to make the donation decision within a $2 \mathrm{~h}$ period from 9.00 AM; "a time frame dictated by the post-mortem examination itself" (Sundqvist et al. 2012, p. 98).

Potential donors and their families reported feeling anxious about the logistics of brain donation and funeral arrangements (Austrom et al. 2011; Boise et al. 2017; Eatough et al. 2012; Harris et al. 2013). Some study participants were worried that following the brain donation their loved one's body would appear disfigured and this would be noticeable at an opencoffin funeral (Angelini et al. 2011; Boise et al. 2017; Garrick et al. 2006). Others experienced delays with the doctor issuing a death certificate, and healthcare professionals being insensitive and/or lacking awareness about their situation (Eatough et al. 2012). One study participant—a donor's friend called Cynthiaexperienced procedural delays and recounted feeling angry with the nursing staff. Cynthia recounted, "I've got to do this for her. I was very aware that this was something, the job she'd asked me to do and I had to do it and these people saying well, we've got to wait you know you've got to wait there isn't a doctor on duty" (Eatough et al. 2012, p. 1281).

\section{Discussion}

This review set out to identify factors informing people's decisions to donate their own or their loved one's brain for research. We identified 14 articles that contribute to answering this question. Overall, the quality of the included literature was very high or high and this is encouraging as it lends weight to the metaethnographic findings. Four universal factors were identified in the literature that inform a person's brain donation decision: contextual knowledge, conceptual understandings, family/friends matter, and personal experience, time and process (Fig. 2). These factors do not stand alone. Rather, they interconnect to inform the complex psychological and social processes behind a person's decision.

We found people's contextual knowledge (which we discuss in terms of health literacy) informs people's donation decisions. Studies often discussed contextual knowledge in terms of participant 'understanding and misunderstanding(s).' Some studies reported on how participant knowledge, values and ideas informed donation outcome rather than on how participant beliefs informed donation outcome 
(although six articles did list religious beliefs as a barrier to donation). In terms of values, for example, Eatough and colleagues explain that for their participants, "the brain is not special but its presence on a laboratory shelf has meaning." (Eatough et al. 2012, p. 1283). The meaning that participants attributed to brain donation for research served to facilitate their grieving processes and offered them a degree of comfort.

Our second finding relates to conceptual understanding of brain donation as a 'good' or altruistic act. Gawande writes, "the only way death is not meaningless is to see yourself as part of something greater: a family, a community, a society. If you don't, mortality is only a horror. But if you do, it is not" (Gawande 2014, p. 127). This sentiment resonates with how donors and their families conceptualised brain donation in our reviewed literature. Potential donors expressed altruistic motivations in their decisionmaking processes and in conversations with family members. People saw brain donation as a way to help others, their family members and descendants, other people with the same condition, or society in general. Brain donation was also a source of comfort and hope for family members. Healthcare professionals strongly influenced people's experiences of donation processes.

Our third finding highlights the influence of family and importance of their involvement in the donation decision process. Knowledge of a family member's wishes prior to their death influenced family members' decisions and donation outcomes. Conversations about donation between potential donors and their family or friends were therefore identified as very important. Such conversations may relieve potential donors' anxiety that their family will not honour their donation decision. Increasing contextual knowledge and health literacy of family members may positively inform donation outcomes.

Our fourth and final key finding is that personal experience, time and process are the external factors that affect donation decisions. The conditions under which the invitation to donate is made influence a potential donors' decision. The literature indicates that a well-timed and personal invitation, received in an appropriate environment is important. In the context of the coronial autopsy, Garrick et al. (2009) found that the timing of the brain donation request influenced their consent rates. In their study, most donation requests were made within $60 \mathrm{~h}$ of the potential donor's death. Their study found that the longer the interval between death and the donation request, the more likely a consent was gained. They explained that families need time to come to terms with the death of their relatives before being approached about donation of organs or tissue (Garrick et al. 2009), which is consistent with other literature (West and Burr 2002). Trujillo Diaz et al. (2018) have recently demystified the processes that support such conversations and donation outcomes. Their article additionally provides a wealth of guidance for effective management of the various processes involved-from advertising, screening and consenting to donor communication and brain harvest processes.

In instances where a donation decision needs to be made quickly (following death), it is important to provide the potential donor's family with information - in the right amount and pitched at the right health literacy level-about donation for research. This provision may be highly influential over donation outcome. For a successful donation outcome these factors must all align: the donor's family has a shared understanding of the donor's wishes, are well informed and do give permission; donation processes are followed in a smooth and timely fashion, and donation must proceed without undue stress toward the donor or their family. This is particularly pertinent given that the donation processes largely occur while family members are in a raw and intense stage of grief over the death of their loved one. We, therefore, urge those involved in brain donation processes to be mindful and empathetic of people's feelings in each of these areas.

What this review is largely missing are the voices of people with healthy brain who are considering brain donation. To what extent are their motivations the same? Population survey research concerning people's brain donation health literacy could help us answer our questions about healthy brain donation motivations and barriers, as could qualitative research with people who have healthy brain about their views, values, and beliefs that inform their donation decisions.

Many factors influence people's donation decision. We have detailed the factors described in the literature. However, gaps remain in what we know. How do people sustain motivation for donation? Although some people maintain their motivation for years and in 
the context of complex donating processes, we know little about how they do this. We also know little about the factors informing the donation of young and/or healthy brains. In this review, only one article focused on the donation of brains from young children. Some different issues arise in that context than from adult brain donation. For example, the relationships between the donors and their family are different, and the agency is differently located. We call for more research that can fill this age-related research gap. In this paper, we have presented findings on voluntary donation and donation through coronial autopsy (see Table 2). Again, different processes and issues are involved, and we know little of how such differences inform donation decisions. Qualitative research in this area would be valuable to those working in brain donation-related fields.

Meta-ethnographic synthesis process

Meta-ethnographic synthesis approach followed for this review enables a rigorous procedure for interpretations about ethnographic and interpretive studies (Noblit and Hare1988). In this systematic review, the research question about the factors people consider important in deciding whether or not to donate their or their loved ones' brain for research guided our inquiry of the paper reviewed. We found that the compilation of findings in key concepts (Table 2) provided a detailed mapping of the influencing factors. These key concepts then provided a platform for analysis and synthesis that extends beyond what an empirical study can offer. Based on this mapping we developed our conceptual framework (Fig. 2) to better understand how the donation decision processes work.

\section{Limitations}

This research only included studies written in English. Studies that only included quantitative research methods were excluded due to our analytical methods. This meant that some important literature was not included in the findings but we have referred to them in our introduction and discussion.

The search term 'brain donation' was used in place of 'organ donation' because we specifically wanted to explore brain donation rather than any other organ donation. It is possible that articles may have been missed where they did not mention brain donation in the title, keywords, or abstract.

\section{Conclusions}

This review included fourteen articles, six of which were appraised as very high quality. We asked, what are the factors people consider important in deciding whether or not to donate their or their loved ones' brain for research? The factors are the contextual knowledge (brain donation health literacy) and conceptual understandings of potential donors and their families (such as altruism); family influences and needs; personal experiences (including conversations with healthcare and donation professionals); time (timing of conversation and of process completions); and donation and funeral processes. These many and complex factors need to align for a positive donation outcome.

Acknowledgements For their significant advice and support, we would like to thank Toni Bruce, Molly Mullen, Missy Morton, and Rebecca Jesson. We also thank the School of Critical Studies in Education Writing group and the School of Curriculum and Pedagogy Writing Group within the Faculty of Education and Social Work at the University of Auckland.

\section{Compliance with ethical standards}

Conflict of interest As the corresponding author of the manuscript which has been submitted to Cell and Tissue Banking, I Meng-Jiun Penny Lin declare all authors (M-J Penny Lin, Tanisha Jowsey, and Maurice A Curtis) do not have any possible conflicts of interest. Our systematic literature review does not involve Human Participants and/or Animals. Thus, inform consent is not applicable.

Open Access This article is distributed under the terms of the Creative Commons Attribution 4.0 International License (http:// creativecommons.org/licenses/by/4.0/), which permits unrestricted use, distribution, and reproduction in any medium, provided you give appropriate credit to the original author(s) and the source, provide a link to the Creative Commons license, and indicate if changes were made.

\section{Appendix 1: Key questions in the Framework for Assessing Qualitative Evaluations (FAQE)}

\author{
Findings
}

1. How credible are the findings? 
2. How has knowledge/understanding been extended by the research?

3. How well does the evaluation address its original aims and purpose?

4. Scope for drawing wider inference-how well is this explained?

5. How clear is the basis of evaluative appraisal?

Design

6. How defensible is the research design?

Sample

7. How well defended is the sample design/target selection of cases/documents?

8. Sample composition/case inclusion-how well is the eventual coverage described?

Data collection

9. How well was the data collection carried out?

Analysis

10. How well has the approach to, and formulation of, the analysis been conveyed?

11. Contexts of data sources-how well are they retained and portrayed?

12. How well has diversity of perspective and content been explored?

13. How well has detail, depth, and complexity (i.e. richness) of the data been conveyed?

\section{Reporting}

14. How clear are the links between data, interpretation, and conclusions-i.e. how well can the route to any conclusions be seen?

15. How clear and coherent is the reporting?
Reflexivity and neutrality

16. How clear are the assumptions/theoretical perspectives/values that have shaped the form and output of the evaluation?

Ethics

17. What evidence is there of attention to ethical issues?

Auditability

18. How adequately has the research process been documented?

\section{References}

Angelini P, Hawkins C, Laperriere N, Bouffet E, Bartels U (2011) Post mortem examinations in diffuse intrinsic pontine glioma: challenges and chances. J Neuro-Oncol 101(1):75-81. https://doi.org/10.1007/s11060-010-0224-7

Austrom MG, Dickinson SLJ, Denny SS, Matthews BR, Gao S, Lu Y (2011) Frontotemporal dementia caregivers and researchers: partnering for brain donation. Am J Alzheimer's Dis Other Dement 26(6):477-483. https://doi.org/10. $1177 / 1533317511424278$

Azizi L, Garrick TM, Harper CG (2006) Brain donation for research: strong support in Australia. J Clin Neurosci 13(4):449-452. https://doi.org/10.1016/j.jocn.2005.06.008

Bilbrey AC, Humber MB, Plowey ED, Garcia I, Chennapragada L, Desai K et al (2018) The impact of Latino values and cultural beliefs on brain donation: results of a pilot study to develop culturally appropriate materials and methods to increase rates of brain donation in this under-studied patient group. Clin Gerontol 41(3):237-248. https://doi. org/10.1080/07317115.2017.1373178

Boise L, Hinton L, Rosen HJ, Ruhl M (2017) Will my soul go to heaven if they take my brain? Beliefs and worries about brain donation among four ethnic groups. Clin Gerontol 57(4):719-734. https://doi.org/10.1093/geront/gnv683

Boyes M, Ward P (2003) Brain donation for schizophrenia research: gift, consent, and meaning. J Med Ethics 29(3):165-168

Campbell R, Pound P, Pope C, Britten N, Pill R, Morgan M, Donovan J (2003) Evaluating meta-ethnography: a synthesis of qualitative research on lay experiences of diabetes and diabetes care. Soc Sci Med 56(4):671-684. https://doi. org/10.1016/S0277-9536(02)00064-3 
Eatough V, Shaw K, Lees A (2012) Banking on brains: insights of brain donor relatives and friends from an experiential perspective. Psychol Health 27(11):1271-1290. https://doi. org/10.1080/08870446.2012.669480

France B, Cridge B, Fogg-Rogers L (2017) Organisational culture and its role in developing a sustainable science communication platform. Int J Sci Educ Part B Commun Publ Engagem 7(2):146-160. https://doi.org/10.1080/ 21548455.2015.1106025

Garrick TM, Howell S, Terwee P, Redenbach J, Blake H, Harper C (2006) Brain donation for research: who donates and why? Cell Tissue Bank 13(5):524-528. https://doi.org/10. 1007/s10561-009-9121-8

Garrick TM, Sundqvist N, Dobbins T, Azizi L, Harper C (2009) Factors that influence decisions by families to donate brain tissue for medical research. Cell Tissue Bank 10(4):309-315. https://doi.org/10.1007/s10561-009-91361

Gawande A (2014) Being mortal. Being mortal: illness, medicine, and what matters in the end. Profile Books, London

Glaser BG, Strauss AL (2017) Discovery of grounded theory: strategies for qualitative research. Routledge, London

Harris C, Kiger A, Counsell C (2013) Attitudes to brain donation for Parkinson's research and how to ask: a qualitative study with suggested guidelines for practice. J Adv Nurs 69(5):1096-1108. https://doi.org/10.1111/j.1365-2648. 2012.06099.x

Jefferson AL, Lambe S, Romano RR, Liu D, Islam F, Kowall N (2013) An intervention to enhance Alzheimer's disease clinical research participation among older African Americans. J Alzheimer's Dis 36(3):597-606. https://doi. org/10.3233/JAD-130287

Kuhta T, Zadikoff C, Simuni T, Martel A, Williams K, Videnovic A (2011) Brain donation-what do patients with movement disorders know and how do they feel about it? Parkinsonism Relat Disord 17(3):204-207. https://doi.org/ 10.1016/j.parkreldis.2010.12.009

Lambe S, Cantwell N, Islam F, Horvath K, Jefferson AL (2011) Perceptions, knowledge, incentives, and barriers of brain donation among African American elders enrolled in an Alzheimer's research program. The Gerontologist 51(1):28-38. https://doi.org/10.1093/geront/gnq063

MacEachen E, Clarke J, Franche R-L, Irvin E, Group, W. R. to W. L. R (2006) Systematic review of the qualitative literature on return to work after injury. Scand J Work Environ Health 32(4):257-269. https://doi.org/10.2307/40967575

Millar T, Walker R, Arango J-C, Ironside J, Harrison D, MacIntyre D et al (2007) Tissue and organ donation for research in forensic pathology: the MRC sudden death brain and tissue bank. J Pathol 213:369-375. https://doi. org/10.1002/path.2247

Noblit GW, Hare RDR (1988) Meta-ethnography: synthesizing qualitative studies. qualitative research methods series, vol 11. Sage, Newbury Park. https://doi.org/10.1097/ 00005053-199007000-00016
Nussbeck SY, Wemheuer WM, Beier K (2015) Why brain banking should be regarded as a special type of biobanking: ethical, practical, and data-management challenges. J Biorepository Sci Appl Med 3(1):3-14. https://doi.org/ 10.2147/BSAM.S75245

O'Brien BC, Harris IB, Beckman TJ, Reed DA, Cook DA (2014) Standards for reporting qualitative research: a synthesis of recommendations. Acad Med J Assoc Am Med Coll 89(9):1245-1251. https://doi.org/10.1097/ACM. 0000000000000388

Padoan CS, Garcia LF, Rodrigues AA, Patusco LM, Atz MV, Kapczinski F et al (2017) "Why throw away something useful?": attitudes and opinions of people treated for bipolar disorder and their relatives on organ and tissue donation. Cell Tissue Bank. https://doi.org/10.1007/ s10561-016-9601-6

Price D (2010) Human tissue in transplantation and research: a model legal and ethical donation framework. Cambridge University Press, Cambridge

Schmitt FA, Wetherby MMC, Wekstein DR, Dearth CMS, Markesbery WR (2001) Brain donation in normal aging: procedures, motivations, and donor characteristics from the Biologically Resilient Adults in Neurological Studies (BRAiNS) project. Gerontologist. https://doi.org/10.1093/ geront/41.6.716

Schnieders T, Danner DD, McGuire C, Reynolds F, Abner E (2013) Incentives and barriers to research participation and brain donation among African Americans. Am J Alzheimer's Dis Other Dement 28(5):485-490. https://doi.org/10. $1177 / 1533317513488922$

Spencer L, Ritchie J, Lewis J, Dillon L (2003) Quality in qualitative evaluation: a framework for assessing research evidence, Government Chief Social Researcher's Office, Cabinet Office. London. https://assets.publishing.service. gov.uk/government/uploads/system/uploads/attachment_ data/file/498322/a_quality_framework_tcm6-38740.pdf. Accessed 18 Sept 2019

Stevens M (1998) Factors influencing decisions about donation of the brain for research purposes. Age Age. https://doi.org/ 10.1093/ageing/27.5.623

Sundqvist N, Garrick TM, Harding A (2012) Families' reflections on the process of brain donation following coronial autopsy. Cell Tissue Bank 13(1):89-101. https://doi.org/ 10.1007/s10561-010-9233-1

Trujillo Diaz D, Hernandez NC, Cortes EP, Faust PL, Vonsattel JPG, Louis ED (2018) Banking brains: a pre-mortem "how to" guide to successful donation. Cell Tissue Bank. https:// doi.org/10.1007/s10561-018-9720-3

West R, Burr G (2002) Why families deny consent to organ donation. Aust Crit Care 15(1):27-32. https://doi.org/10. 1016/S1036-7314(02)80041-8

Publisher's Note Springer Nature remains neutral with regard to jurisdictional claims in published maps and institutional affiliations. 